\section{Commentary: Does a "less is more" approach reduce delirium in patients undergoing coronary artery bypass grafting?}

\author{
D. Scott Kehler, $\mathrm{PhD},{ }^{\mathrm{a}}$ and \\ Rakesh C. Arora, MD, PhD, FRCSC ${ }^{\text {b,c }}$
}

Delirium and postoperative cognitive dysfunction (POCD) are common in patients who undergo cardiac surgery with cardiopulmonary bypass. ${ }^{1}$ There is an ongoing debate regarding the neurocognitive benefits of off-pump coronary artery bypass grafting (OPCAB) relative to on-pump procedures. A proposed theory with the use of OPCAB is the reduced neuroinflammatory response. with subsequent attenuation in neuropsychiatric complications such as delirium and cognitive decline ${ }^{2}$; however, this notion remains to be elucidated. In their study in this issue of the Journal, Szwed and colleagues ${ }^{3}$ have sought to address this knowledge gap by studying a subset of patients within a single-center, randomized controlled trial (NCT03074604).

Szwed and colleagues ${ }^{3}$ compared 3 OPCAB techniques in 191 elective patients: (1) conventional OPCAB with vein grafts $(n=64)$; (2) OPCAB (with a partial clamp for proximal anastomoses) in which carbon dioxide was applied by field flooding ( $\mathrm{n}=64)$; and (3) anaortic (ie, "no-touch") OPCAB without manipulation of the ascending aorta $(n=63)$. The main outcomes reported here were the incidence of delirium according to the Confusion Assessment Method for the Intensive Care Unit within 7 days of surgery and cognitive dysfunction (a $20 \%$ reduction in at

\footnotetext{
From the ${ }^{\mathrm{a}}$ Department of Physiotherapy, Dalhousie University, Halifax, Nova Scotia, Canada; 'bepartment of Surgery, University of Manitoba, Winnipeg, Manitoba, Canada; and ${ }^{\mathrm{c} C a r d i a c}$ Sciences Program, St Boniface Hospital, Winnipeg, Manitoba, Canada.

Disclosures: Dr Arora has an unrestricted educational grant from Pfizer Canada Inc and has received honoraria from Mallinckrodt Pharmaceutical and Abbott Nutrition for work unrelated to this article. Dr Kehler has nothing to disclose with regard to commercial support.

Received for publication Oct 22, 2019; revisions received Oct 22, 2019; accepted for publication Oct 23, 2019; available ahead of print Nov 13, 2019.

Address for reprints: Rakesh C. Arora, MD, PhD, FRCSC, St Boniface Hospital, CR3015, 369 Tache Ave, Winnipeg, Manitoba R2H 2A6, Canada (E-mail: rakeshcarora@gmail.com).

J Thorac Cardiovasc Surg 2021;161:1285-6

$0022-5223 / \$ 36.00$

Copyright (c) 2019 by The American Association for Thoracic Surgery

https://doi.org/10.1016/j.jtcvs.2019.10.131
}

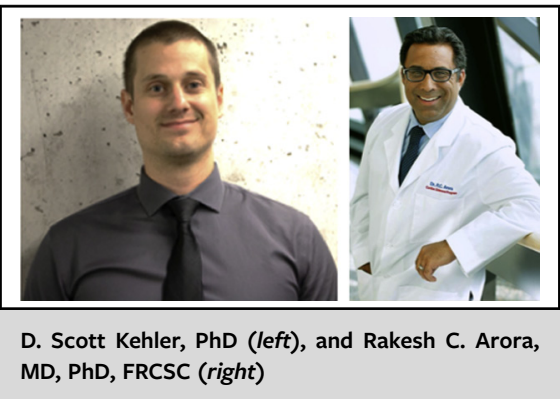

CENTRAL MESSAGE

Off-pump CABG without aortic manipulation may have neurocognitive protective benefits. It will be enlightening to determine the mechanisms of reduced risk and whether the frail patient can benefit.

least 2 domains in a battery of neurocognitive tests) 7 days postoperatively. In the study, the incidence of delirium was lower with anaortic OPCAB $(12.5 \%)$ than with either carbon dioxide field flooding $(32.8 \%)$ or conventional OPCAB technique $(36 \%)$. Cognitive performance 7 days after surgery followed a similar trend: anaortic OPCAB had the lowest incidence of cognitive decline $(9.5 \%)$, followed by $\mathrm{CO}_{2}$ field flooding $(28.1 \%)$, and then conventional OPCAB (34.4\%), mirroring previous observational studies. ${ }^{4}$ Interestingly, the relative ratio of delirium to postoperative cognitive decline followed a similar pattern ( $76 \%$ vs $85 \%$ vs $95 \%$ ) for anaortic, carbon dioxide field flooding, and conventional OPCAB, respectively.

The participants in this study were relatively young (approximately 65 years old) with a low risk for perioperative mortality (approximately 1\%). Although in-hospital mortality for OPCAB remains low, the incidence of neuropsychiatric complications is often higher in older and frailer patients. ${ }^{5,6}$ It may be of greater interest to understand the effect of anaortic OPCAB on neuropsychiatric function within a frailer surgical patient population. ${ }^{7}$

Important to note was the high frequency of antipsychotic use (approximately 24\%) reported in this study. Current society guidelines recommend prescribing antipsychotics only for patients who have significant distress secondary to symptoms of delirium such as anxiety, fearfulness, and 
hallucinations. ${ }^{8}$ The predominant delirium motoric subtype were hypoactive, so it is unclear why the rate of antipsychotic use was this high. Furthermore, if delirium duration was affected by the surgical technique used, such a high antipsychotic prescription may have a long-term impact on POCD.

Szwed and colleagues ${ }^{3}$ hypothesize that the use of the anaortic technique would avoid a major source of solid microemboli, but this was not directly measured in their analysis. Further, others have suggested that atherosclerotic burden, rather than microemboli, increases the risk of POCD. ${ }^{10}$ This study by Szwed and colleagues ${ }^{3}$ starts an important discussion of tailoring a surgical technique to patients with a higher risk for delirium and POCD. The planned magnetic resonance imaging analysis in the parent study may provide new mechanistic data by which an anaortic OPCAB may reduce the risk of these important patient-centered outcomes, and it will be of interest.

\section{References}

1. Brown CH IV, Probert J, Healy R, Parish M, Nomura Y, Yamaguchi A, et al. Cognitive decline after delirium in patients undergoing cardiac surgery. Anesthesiology. 2018;129:406-16.
2. Ramlawi B, Rudolph JL, Mieno S, Khabbaz K, Sodha NR, Boodhwani M, et al Serologic markers of brain injury and cognitive function after cardiopulmonary bypass. Ann Surg. 2006;244:593-601.

3. Szwed K, Pawliszak W, Szwed M, Tomaszewska M, Anisimowicz L, Borkowska A. Reducing delirium and cognitive dysfunction after off-pump coronary bypass: a randomized trial. J Thorac Cardiovasc Surg. 2021;161: 1275-82.e4.

4. O'Neal JB, Billings FT IV, Liu X, Shotwell MS, Liang Y, Shah AS, et al. Risk factors for delirium after cardiac surgery: a historical cohort study outlining the influence of cardiopulmonary bypass. Can J Anaesth. 2017;64: 1129-37.

5. Jung P, Pereira MA, Hiebert B, Song X, Rockwood K, Tangri N, et al. The impact of frailty on postoperative delirium in cardiac surgery patients. J Thorac Cardiovasc Surg. 2015;149:869-75. e1-2.

6. Sepehri A, Beggs T, Hassan A, Rigatto C, Shaw-Daigle C, Tangri N, et al. The impact of frailty on outcomes after cardiac surgery: a systematic review. J Thorac Cardiovasc Surg. 2014;148:3110-7.

7. Lytwyn J, Stammers AN, Kehler DS, Jung P, Alexander B, Hiebert BM, et al. The impact of frailty on functional survival in patients 1 year after cardiac surgery. $J$ Thorac Cardiovasc Surg. 2017;154:1990-9.

8. Devlin JW, Skrobik Y, Gélinas C, Needham DM, Slooter AJC, Pandharipande PP, et al. Clinical practice guidelines for the prevention and management of pain, agitation/sedation, delirium, immobility, and sleep disruption in adult patients in the ICU. Crit Care Med. 2018;46:e825-73.

9. Rudolph JL, Jones RN, Grande LJ, Milberg WP, King EG, Lipsitz LA, et al. Impaired executive function is associated with delirium after coronary artery bypass graft surgery. J Am Geriatr Soc. 2006;54:937-41.

10. Rudolph JL, Babikian VL, Treanor P, Pochay VE, Wigginton JB, Crittenden MD, et al. Microemboli are not associated with delirium after coronary artery bypass graft surgery. Perfusion. 2009;24:409-15. 